\title{
PENGARUH JENIS REFRIGERANT DAN DIAMETER PIPA KAPILER TERHADAP KINERJA AC SPLIT
}

\author{
Tabah Priangkoso*, Nur Edy Santoso, Teguh Apriyanto dan Muhammad Dzulfikar \\ Jurusan Teknik Mesin, Fakultas Teknik Universitas Wahid Hasyim \\ Jl. Menoreh Tengah X/22, Sampangan, Semarang 50236. \\ *Email: tabah@unwahas.ac.id
}

\begin{abstract}
Abstrak
Refrigerant $R-22$ yang dipakai untuk AC sangat berperan besar dalam proses penipisan lapisan ozon dan pemanasan global, sehingga mulai dilarang pemakaiannya. $R-32$ dan $R$ $410 A$ merupakan Refrigerant yang ramah lingkungan untuk pengganti Refrigerant $R-22$. Tujuan penelitian ini adalah membandingan COP pada AC split menggunakan Refrigerant $R$ 22, $R$-32 dan R-410A, karena COP merupakan ukuran untuk menilai kinerja suatu AC. Adapun tujuan lain yaitu membandingkan pemakaian daya listrik kompresor ketika menggunakan ketiga jenis Refrigerant tersebut. Penelitian yang dilakukan adalah melakukan variasi pemakaian bahan pendingin pada AC split $1 / 2$ PK. Bahan pendingin Refrigerant yang digunakan adalah $R-22$, kemudian $R-32$, dan yang terakhir adalah $R-410 A$. Dari hasil penelitian didapatkan pada penggunaan $R-22$ rata-rata nilai $C O P$ adalah 7,11 . Pada penggunaan $R-32$ rata-rata nilai $C O P$ adalah 5,23. Sedangkan pada penggunaan $R-410 A$ rata-rata nilai COP adalah 4,68. Dari hasil tersebut dilihat bahwa COP $R-22$ paling besar, sedangkan pemakaian daya listrik kompresor yang menggunakan $R-22$ paling rendah dibandingkan menggunakan $R-32$ dan $R-410 A$.
\end{abstract}

Kata kunci: $A C, C O P$, refrigerant

\section{PENDAHULUAN}

Kinerja AC split dipengaruhi banyak tiga faktor utama, yaitu faktor lingkungan, faktor Refrigerant (fluida pendingn), dan faktor komponen AC split sebagai sistem mesin pendingin. Temperatur dan kelembaban udara lingkungan mempengaruhi beban pendinginan yang harus ditanggung oleh AC, sehingga mempengaruhi kinerja AC. Jenis Refrigerant dan komponen AC seperti evaporator, kondensor, kompresor, dan pipa kapiler; sangat mempengaruhi kinerja AC split.

Halokarbon R22 merupakan refirgerant yang paling umum digunakan di dunia, namun karena sifatnya yang merusak ozon, maka diupayakan menggantinya dengan Refrigerant yang lebih ramah lingkungan.

Sesuai dengan Protokol Montreal, R22 akan dilarang secara total penggunaannya mulai 1 Januari 2030, sehingga diperlukan Refrigerant pengganti yang memungkinkan AC memiliki kinerja lebih baik, Dua jenis Refrigerant yang disarankan sebagai pengganti R22 untuk AC adalah R32 dan R410A yang lebih ramah lingkungan dibanding R22. Sebagai penggantinya, digunakan R410A untuk semua jenis AC dan refrigerator. Sesuai dengan tuntutan penggunaan Refrigerant yang makin ramah lingkungan, saat ini mulai digunakan R32 yang memiliki indeks pendinginan paling tinggi dibanding kedua jenis Refrigerant lainnya. Perusahaan-perusahaan kompresor juga mulai mengalihkan penggunaan R22 ke R410A atau R32 untuk mendinginkan ruangan (Hadya, Prasad, \& Akella, 2015).

Di sisi lain, kemungkinan untuk meningkatkan kinerja AC split dapat dilakukan melalui modifikasi pipa kapiler, mengingat komponen ini yang paling mudah dimodifikasi dibanding komponen lain seperti evaporator, kondensor, atau kompresor. Selain itu, modifikasi pipa kapiler juga paling murah untuk dilakukan.

Penelitian ini bertujuan untuk mengetahui pengaruh jenis Refrigerant terhadap kinerja AC split menggunakan Refrigerant R22 untuk dibandingkan dengan penggantinya R410A dan R32. Selain itu, akan diuji juga pengaruh diameter pipa kapiler sebagai tindakan modifikasi terhadap kinerja AC split. AC split yang digunakan sebagai alat eksperimen adalah AC split merek Changhong CSC-05T1/A01174, 1/2 PK.

\section{METODE}

Set up alat eksperimen dilakukan sesuai skema pada Gambar 1. P1, P2, P3, dan P4 adalah pengukur tekanan Refrigerant, sedangkan $\mathrm{T} 1, \mathrm{~T} 2, \mathrm{~T} 3$, dan $\mathrm{T} 4$ adalah termometer untuk mengukur temperatur Refrigerant. V1, V2, dan V3 adalah katup 
untuk mengalirkan Refrigerant melalui pipa kapiler yang dikehendaki.

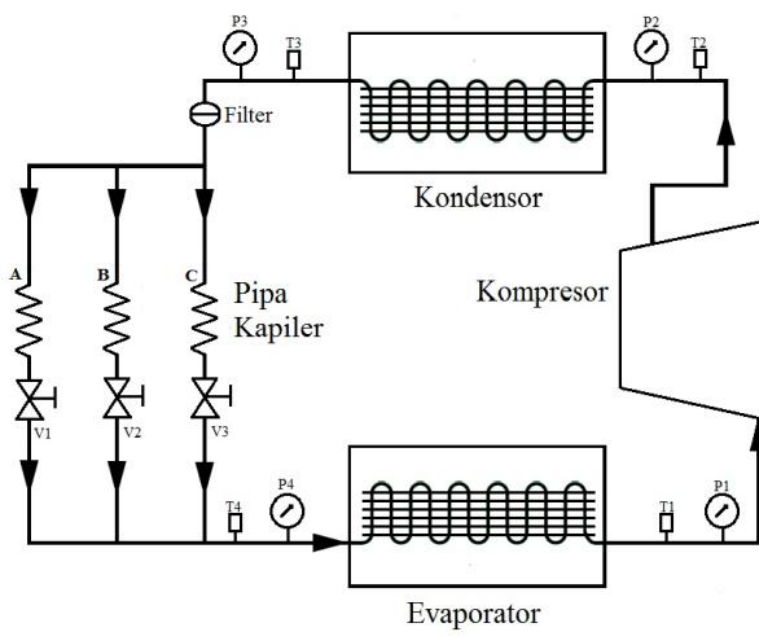

\section{eksperimen}

Skema pada Gambar 1 kemudian diterapkan pada Gambar 2 sebagai susunan alat eksperimen berupa AC split lengkap dengan evaporator, kompresor, kondensor, pipa kapiler; dilengkapi dengan pengukur tekanan, termometer, dan katup untuk mengatur pipa kapiler mana yang akan digunakan.

Pengujian pengaruh jenis Refrigerant kinerja AC split dilakukan menggunakan tiga jenis Refrigerant yaitu R22, R410A, dan R32. R22 digunakan sebagai Refrigerant kontrol karena akan digantikan R410A dan R32.

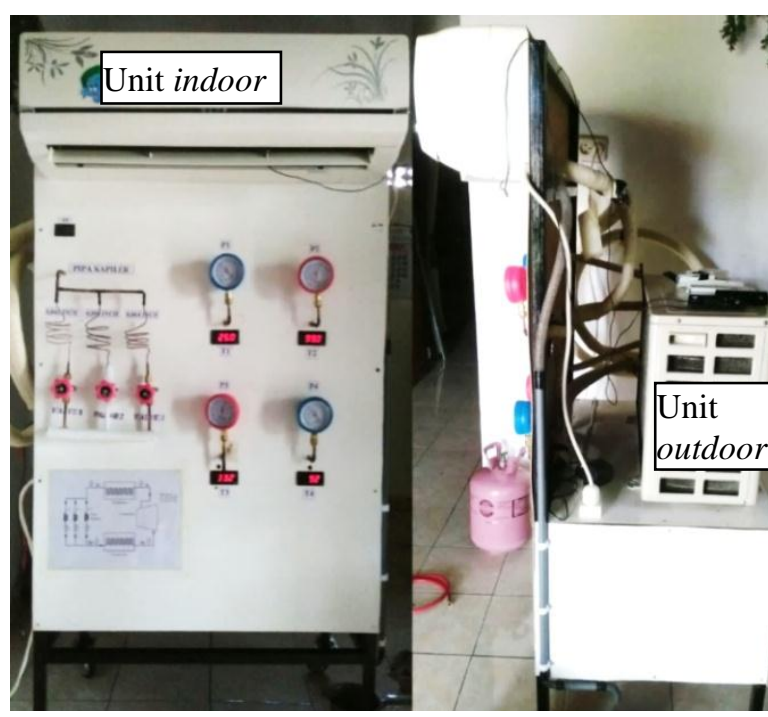

Gambar 2. Susunan alat eksperimen
Kinerja AC split diukur menggunakan coefficient of performance (COP) yang dihitung berdasarkan persamaan (Stoecker, 1986)

$$
C O P=\frac{q_{e}}{W}
$$

dimana:

$q_{e}=$ kalor diserap oleh evaporator utk setiap $\mathrm{kg}$ Refrigerant $(\mathrm{kJ} / \mathrm{kg})$;

$W=$ kerja kompresi oleh kompresor untuk setiap $\mathrm{kg}$ Refrigerant $(\mathrm{kJ} / \mathrm{kg})$

Kalor yang diserap oleh evaporator atau efek pendinginan $q_{e}$ dihitung sebagai selisih entalpi Refrigerant keluar dan masuk evaporator menggunakan persamaan (Stoecker, 1986)

$$
q_{e}=h_{1}-h_{4}
$$

dimana:

$h_{1}=$ entalpi Refrigerant keluar dari evaporator $(\mathrm{kJ} / \mathrm{kg})$

$h_{4}=$ entalpi Refrigerant masuk ke evaporator $(\mathrm{kJ} / \mathrm{kg})$

Kerja kompresor $W$ dihitung berdasarkan kenaikan entalpi Refrigerant akibat masukan daya dari kompresor. $W$ dihitung menggunakan persamaan (Stoecker, 1986)

$$
W=h_{2}-h_{1}
$$

dimana:

$h_{1}=$ entalpi Refrigerant masuk ke kompresor $(\mathrm{kJ} / \mathrm{kg})$

$h_{2}=$ entalpi Refrigerant keluarr dari kompresor $(\mathrm{kJ} / \mathrm{kg})$

Besarnya entalpi diperoleh dari kurva Refrigerant yang diberikan oleh Moran (2006) dan ASHRAE (2001) dengan melihat kondisi tekanan dan temperatur pengukuran Refrigerant pada P1 dan T1, P2 dan T2, serta P4 dan T4. Hasil pengukuran tekanan dan temperatur diplot pada kurva untuk mendapatkan harga entalpi.

Langkah pertama untuk melakukan eksperimen adalah menguras Refrigerant yang berada di dalam AC split, kemudian diisi dengan R22 yang masih segar sampai pada tekanan antara 60-70 Psig, sesuai dengan spesifikasi kompresor AC split. Pengujian kinerja dilakukan selama 90 menit pada kondisi lingkungan $30,1^{\circ} \mathrm{C}$ dan $\mathrm{RH} \quad 76 \%$ dengan 
pengaturan termostat $16^{\circ} \mathrm{C}$, sehingga kompresor tidak berhenti bekerja karena evaporator selalu berhubungan dengan udara lingkungan. Pencatatan kondisi Refrigerant di tiap titik dilakukan setiap 15 menit. Sebelum dilakukan pencatatan, AC dinyalakan selama 30 menit terlebih dahulu agar Refrigerant mengalir dengan sempurna.

Tahap berikutnya mengganti R22 dengan R410A dengan cara menguras R22 dan memasukkan R410A ke sistem AC split. Pengujian dilakukan dengan cara yang sama, yaitu mencatat kondisi Refrigerant di tiap titik setiap 15 menit selama 90 menit. Prosedur yang sama juga dilakukan untuk R32.

Pengujian pengaruh diameter pipa kapiler terhadap kinerja AC split dilakukan menggunakan Refrigerant R22 dengan panjang pipa kapiler $78 \mathrm{~cm}$, sesuai dengan spesifikasi AC split. Pengujian dilakukan dengan menutup dua katup sehingga Refrigerant hanya mengalir di satu pipa kapiler. Diameter pipa kapiler yang dipilih 0,042, 0,054, dan 0,064 in karena mudah didapat di pasar. Pencatatan dilakukan setiap 15 menit selama 90 menit setelah AC split bekerja 30 menit.

\section{HASIL DAN PEMBAHASAN Pengujian Refrigerant}

Hasil pengukuran tekanan dan temperatur Refrigerant pada $\mathrm{P} 1$ dan $\mathrm{T} 1$ serta $\mathrm{P} 4$ dan $\mathrm{T} 4$, dengan mengkonfirmasi pada kurva Refrigerant dan menggunakan persamaan (2) menunjukkan bahwa R32 memiliki efek pendinginan tertinggi dibanding R410A dan R22 yang paling rendah efek pendinginannya. Hal dapat dilihat pada Gambar 3. Hal ini sesuai dengan sifat dari R32 yang memiliki cooling capacity lebih tinggi dibanding R22 dan R410A, serta R410A yang memiliki cooling capacity lebih tinggi dari R22 (Anonimous, 2015).

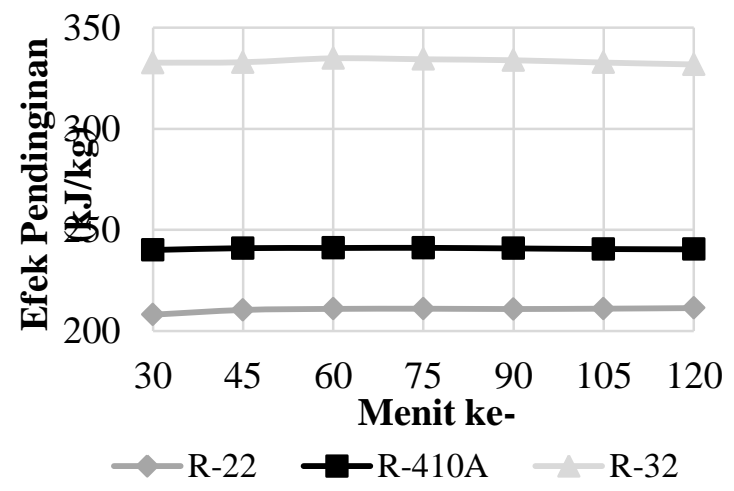

Gambar 3. Efek pendinginan pada evaporator
Tabel 1 menunjukkan bahwa pengukuran dari waktu ke waktu setelah 30 menit AC split hidup menunjukkan efek pendinginan yang merupakan serapan kalor oleh evaporator dari udara lingkungan tidak menunjukkan perubahan yang berarti. Rata-rata efek pendinginan R22 sebesar 210,5 kJ/kg, R410A sebesar 240,1 kJ/kg, dan R32 sebesar 333,3 $\mathrm{kJ} / \mathrm{kg}$.

Tabel 1. Hubungan jenis Refrigerant terhadap efek pendinginan pada evaporator $(\mathrm{kJ} / \mathbf{k g})$

\begin{tabular}{cccc}
\hline Menit ke & R22 & R410A & R32 \\
\hline 30 & 208,0 & 240,0 & 332,7 \\
45 & 210,4 & 240,9 & 332,9 \\
60 & 210,9 & 241,0 & 334,9 \\
75 & 211,0 & 241,1 & 334,4 \\
90 & 210,8 & 240,8 & 333,9 \\
105 & 211,0 & 240,5 & 332,7 \\
120 & 211,3 & 240,4 & 331,8 \\
Rerata & 210,5 & 240,7 & 333,3 \\
\hline
\end{tabular}

Efek pendinginan dihasilkan dari kerja masuk yang diberikan oleh kompresor. Kerja kompresor perlu dihitung menggunakan persamaan (2) untuk menetapkan COP dari masing-masing Refrigerant menggunakan persamaan (1).

Berpedoman pada hasil pengukuran $\mathrm{P} 1$, $\mathrm{T} 1$, P2, dan T2, dengan mengkonfirmasi pada kurva Refrigerant diperoleh kerja kompresor yang diberikan ke Refrigerant.

Tabel 2. Hubungan jenis Refrigerant dengan kerja kompresor $(\mathrm{kJ} / \mathrm{kg})$

\begin{tabular}{cccc}
\hline Menit ke & R22 & R410A & R32 \\
\hline 30 & 28,5 & 44,0 & 55,8 \\
45 & 28,8 & 49,6 & 56,6 \\
60 & 29,1 & 51,2 & 59,7 \\
75 & 29,9 & 53,8 & 64,1 \\
90 & 30,2 & 54,1 & 68,5 \\
105 & 30,3 & 54,4 & 72,1 \\
120 & 30,4 & 54,7 & 74,6 \\
Rerata & 29,6 & 51,7 & 64,5 \\
\hline
\end{tabular}

Pada Tabel 2 terlihat bahwa kerja kompresor tertinggi terjadi pada R32 sebesar $64,5 \mathrm{~kJ} / \mathrm{kg}$, disusul R410A sebesar $51,7 \mathrm{~kJ} / \mathrm{kg}$ dan R22 sebesar $64,5 \mathrm{~kJ} / \mathrm{kg}$. Data ini menunjukkan bahwa penggunaan R32 sebagai Refrigerant membutuhkan daya lebih besar dari pada R410A maupun R22. R22 sendiri memerlukan daya yang lebih rendah dibanding R32 maupun R410A. 


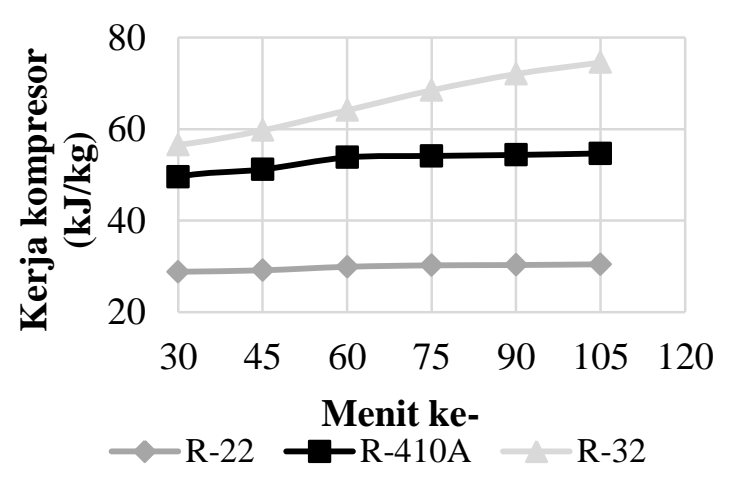

Gambar 4. Kerja kompresor diberikan kepada Refrigerant

Kerja kompresor untuk rerfrigerant $\mathrm{R} 32$ memang paling tinggi dibanding penggunaan $\mathrm{R} 22$ atau R410A, tetapi R32 memiliki cooling capacity yang lebih besar sehingga COPnya lebih tinggi dibanding R410A. Sebaliknya, R410A memiliki COP lebih rendah karena kerja kompresor yang tinggi dibanding cooling capacitynya, R32 memiliki perbandingan yang baik antara cooling capacity dan kerja kompresor.

Pada Gambar 4 terlihat bahwa kerja kompresor meningkat seiring berjalannya waktu. Kenaikan kerja kompresor menunjukkan jika kompresor harus menggunakan daya yang lebih besar untuk mempertahankan cooling capacity tetap maksimum. Kenaikan terbesar pada R32 yang memiliki cooling capacity tertinggi dibanging yang lainnya. Peningkatan kerja kompresor dengan efek pendinginan yang relatif tetap seiring waktu menyebabkan menurunnya COP sebagaimana terlihat pada Gambar 5 dan Tabel 3.

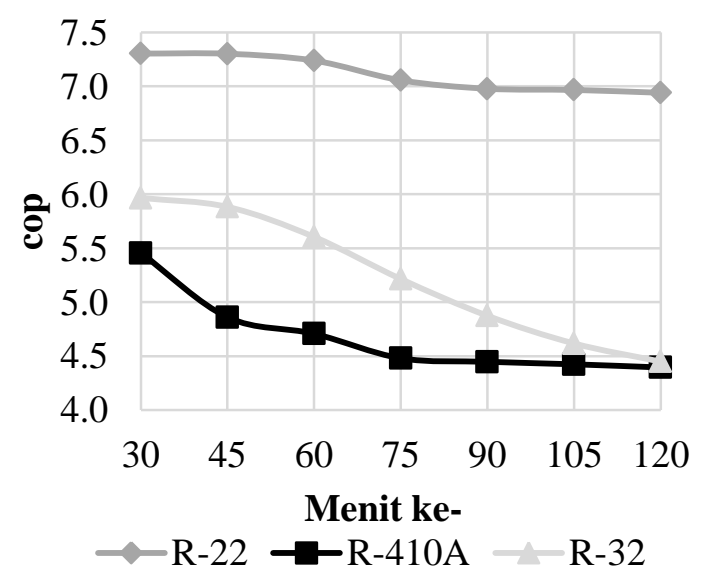

Gambar 5. COP AC split
Tabel 3. Hubungan jenis Refrigerant dengan COP AC split

\begin{tabular}{cccc}
\hline Menit ke & R22 & R410A & R32 \\
\hline 30 & 7,3 & 5,5 & 6,0 \\
45 & 7,3 & 4,9 & 5,9 \\
60 & 7,2 & 4,7 & 5,6 \\
75 & 7,1 & 4,5 & 5,2 \\
90 & 7,0 & 4,4 & 4,9 \\
105 & 7,0 & 4,4 & 4,6 \\
120 & 6,9 & 4,4 & 4,4 \\
Rerata & 7,1 & 4,7 & 5,2 \\
\hline
\end{tabular}

Rata-rata COP tertinggi sebesar 7,1 terdapat pada R22 dan terendah sebesar 5,2 terdapat pada R32. R32 memiliki cooling capacity terbesar, juga memerlukan daya lebih besar. Namun demikian, meskipun R32 memiliki COP paling rendah, Refrigerant ini mempunyai kemampuan pendinginan paling besar. R22 memiliki COP yang lebih baik dibanding R410A dikonfirmasi oleh Jadhav dan Mali (2017). Bolaji (2012) juga menyatakan hal yang sama dari hasil pengujian R410A sebagai pengganti R22. Sementara itu, (Hadya, Prasad, \& Akella (2015) mengkonfirmasi bahwa COP R32 adalah yang terbaik di antara ketiganya, disusul R22.

Antunes dkk (2014) yang melakukan eksperimen menggunakan R410A dan R32 untuk AC yang dispesifikasi menggunakan R22. Kesimpulannya, R32 dan R410A dapat digunakan sebagai pengganti R22 pada mesin AC yang dispesifikasi menggunakan R22. Selain itu, COP R32 lebih tinggi dibanding R22 dan R410A, sedangkan COP R22 lebih tinggi dari R410A.

Dengan mengingat bahwa R22 sangat merusak ozon, maka R410A dan R32 dapat digunakan sebagai pengganti R22. Untuk memperoleh COP terbaik disarankan untuk menggunakan R410A, sedangkan untuk mendapatkan efek pendinginan yang besar disarankan menggunakan R32.

\section{Pengujian diameter pipa kapiler}

Pada pengujian pengaruh diameter pipa kapiler terhadap kinerja AC split, kapasitas pendinginan pada evaporator terbesar diperoleh pada penggunaan diameter pipa kapiler 0,054 in sebesar rata-rata $209,9 \mathrm{~kJ} / \mathrm{kg}$ sebagaimana terlihat pada Gambar 6 dan Tabel 4.

Kapasitas pendinginan cenderung stabil untuk penggunaan ketiga diameter pipa kapiler seiring berjalannya waktu. Kenaikan terjadi pada dia 0,054 in di 30 menit pertama, namun kemudian stabil. Secara keseluruhan, efek 
pendinginan terbaik didapatkan pada penggunaan pipa kapiler berdiameter 0,054 in.

Tabel 4. Hubungan diameter pipa kapiler dengan $(\mathrm{kJ} / \mathrm{kg})$ kapasitas pendinginan evaporator

\begin{tabular}{clrr}
$\begin{array}{c}\text { Menit } \\
\text { ke- }\end{array}$ & \multicolumn{3}{l}{ Diameter pipa kapiler (in) } \\
$\mathbf{0 , 0 4 2}$ & $\mathbf{0 , 0 5 4}$ & $\mathbf{0 , 0 6 4}$ \\
\hline 30 & 204,5 & 205,5 & 192,4 \\
45 & 205,1 & 208,0 & 192,3 \\
60 & 205,4 & 210,7 & 192,2 \\
75 & 205,8 & 211,0 & 192,4 \\
90 & 206,2 & 211,1 & 192,4 \\
105 & 206,3 & 211,4 & 192,4 \\
120 & 206,1 & 211,7 & 192,4 \\
Rerata & 205,6 & 209,9 & 192,4 \\
\hline
\end{tabular}

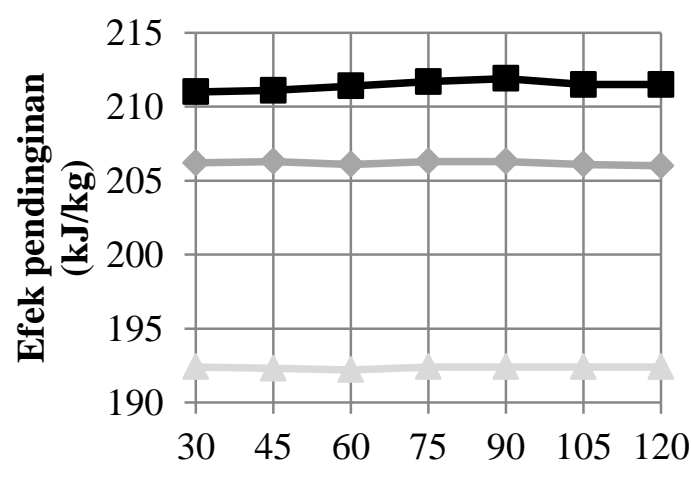

Menit ke-

Gambar 6. Efek pendinginan pada evaporator pada penggunaan pipa kapiler diameter $0,042,0,054$, dan 0,064 in

Tabel 5 memperlihatkan bahwa kerja kompresor tertinggi terdapat pada penggunaan pipa kapiler berdiameter 0,064 in sebesar ratarata $35,0 \mathrm{~kJ} / \mathrm{kg}$, sementara penggunaan pipa kapiler yang lain lebih kecil. Penggunaan pipa kapiler berdiameter 0,054 in mengharuskan kompresor memberikan kerja rata-rata 29,3 $\mathrm{kJ} / \mathrm{kg}$ dan $26,5 \mathrm{~kJ} / \mathrm{kg}$ untuk penggunaan pipa kapiler berdiameter 0,042 in.

Pada Tabel 7 terlihat bahwa COP tertinggi terjadi pada penggunaan pipa kapiler berdiameter 0,042 in dengan rata-rata COP sebesar 7,8. COP terendah terjadi pada penggunaan pipa kapiler berdiameter 0,064 in sebesar 5,5. Angka COP yang rendah ini merupakan konsekuensi dari tingginya kerja kompresor dibanding efek pendinginan evaporator. Begitu juga sebaliknya pada penggunaan pipa kapiler berdiameter 0,042. Efek pendinginan yang rendah juga dibarengi dengan rendahnya kerja kompresor sehingga menyebabkan COP yang tinggi dibanding lainnya.

\section{Tabel 5. Hubungan diameter pipa kapiler} dengan

kerja kompresor (kJ/kg)

\begin{tabular}{cccc} 
Menit & \multicolumn{3}{c}{ Diameter pipa kapiler (in) } \\
ke- & $\mathbf{0 , 0 4 2}$ & $\mathbf{0 , 0 5 4}$ & $\mathbf{0 , 0 6 4}$ \\
\hline 30 & 24,7 & 27,5 & 33,7 \\
45 & 26,2 & 28,6 & 34,8 \\
60 & 26,5 & 29,5 & 35,0 \\
75 & 26,5 & 29,9 & 35,2 \\
90 & 26,8 & 30,0 & 35,1 \\
105 & 27,3 & 29,9 & 35,4 \\
120 & 27,3 & 30,0 & 35,5 \\
Rerata & 26,5 & 29,3 & 35,0 \\
\hline
\end{tabular}

Kerja kompresor cenderung meningkat seiring berjalannya waktu sebagaimana terlihat pada Gambar 7. Hal ini menunjukkan kompresor semakin lama harus memberikan daya semakin besar untuk mempertahankan efek pendinginan. Daya kompresor yang tinggi akan berpengaruh pada COP dimana COP akan menurun sesuai dengan peningkatan kerja kompresor sementara tidak ada peningkatan efek pendinginan pada evaporator.

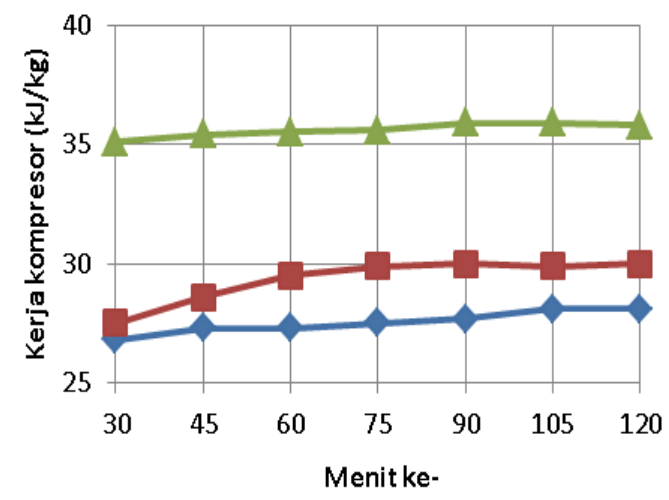

Gambar 7. Kerja kompresor pada penggunaan pipa kapiler diameter 0,042 , 0,054 , dan 0,064 in

Pada Tabel 6 diperlihatkan bahwa ratarata COP tertinggi diperoleh dari penggunaan pipa kapiler berdiameter 0,042 in sebesar ratarata 7,8 , disusul penggunaan pipa kapiler berdiameter 0,054 in sebesar rata-rata 7,2 dan penggunaan pipa kapiler berdiameter 0,064 memberikan COP sebesar rata-rata 5,5. COP yang lebih tinggi menunjukkan bahwa AC split memiliki kinerja lebih baik karena memerlukan energi lebih kecil untuk menghasilkan efek pendinginan yang sama. 
Tabel 6. Hubungan diameter pipa kapiler dengan

\section{COP}

\begin{tabular}{cccc}
\hline \multirow{2}{*}{ Menit ke- } & \multicolumn{3}{c}{ Diameter pipa kapiler (in) } \\
& $\mathbf{0 , 0 4 2}$ & $\mathbf{0 , 0 5 4}$ & $\mathbf{0 , 0 6 4}$ \\
\hline 30 & 8,3 & 7,5 & 5,7 \\
45 & 7,8 & 7,3 & 5,5 \\
60 & 7,7 & 7,1 & 5,5 \\
75 & 7,8 & 7,1 & 5,5 \\
90 & 7,7 & 7,0 & 5,5 \\
105 & 7,6 & 7,1 & 5,4 \\
120 & 7,6 & 7,1 & 5,4 \\
Rerata & 7,8 & 7,2 & 5,5 \\
\hline
\end{tabular}

Penggunaan pipa kapiler dengan 3 diameter yang berbeda menunjukkan penurunan COP seiring berjalannya waktu. Hal sesuai dengan meningkatnya kerja kompresor untuk memperoleh efek pendinginan. Penggunaan pipa kapiler berdiameter 0,042 in memberikan COP tertinggi di sepanjang waktu, sedangkan penggunaan pipa kapiler berdiameter 0,064 in memberikan COP terendah di sepanjang waktu sebagaimana diperlihatkan Gambar 8.

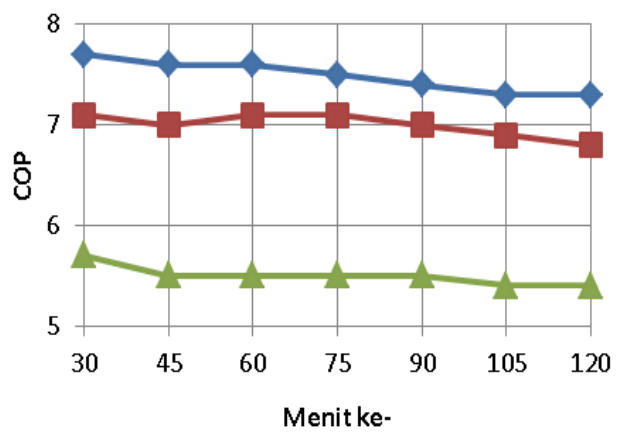

Gambar 8. COP pada penggunaan pipa kapiler diameter $0,042,0,054$, dan 0,064 in

Hasil pengujian ini menunjukkan bahwa penggunaan pipa kapiler dengan diameter terkecil 0,042 in menghasilkan kinerja yang lebih baik, digambarkan dengan COP tinggi, dibanding diameter lainnya. Hal ini disebabkan diameter yang lebih kecil memberikan hambatan lebih besar, sehingga efek penurunan tekanan Refrigerant menjadi lebih efektif.

Efek diameter pipa kapiler dalam meningkatkan COP dapat dilihat jika pipa kapiler yang berbeda diameternya mempunyai panjang yang sama. Pipa kapiler berdiameter yang lebih besar tapi lebih panjang dapat mempunyai efek yang sama dengan pipa kapiler berdiameter kecil tetapi pendek (Akella, 2017). Dengan demikian, jika digunakan pipa kapiler berdiameter besar, maka diperpanjang untuk memberikan efek penurunan tekanan yang sama dengan pipa kapiler berdiameter kecil, mengingat semakin panjang pipa kapiler akan meningkatkan efek pendinginan yang meningkatkan COP (Reddy, D., Bhramara, P., \& Govindarajulu, K., 2012).

\section{KESIMPULAN}

1. Refrigerant R32 memiliki COP paling rendah, tetapi mempunyai cooling capacity paling besar dibanding R22 dan R410A. Sebaliknya, R410A memiliki COP lebih tinggi dari R32, namun memiliki cooling capacity lebih rendah dari R32. COP terbaik didapatkan dari penggunaan R22, namun mengingat R22 tidak ramah lingkungan, sebagai penggantinya dapat digunakan R32 atau R410A. Kedua Refrigerant ini dapat digunakan pada mesin AC split yang bisanya menggunakan R22 sebagai Refrigerant.

2. Pengecilan diameter pipa kapiler meningkatkan COP karena meningkatnya efek pendinginan pada evaporator. Peningkatan COP karena penggunaan pipa kapiler berdiameter kecil dapat diperoleh jika pipa kapiler mempunyai panjang yang sama.

\section{DAFTAR PUSTAKA}

Akella, S., (2017), Capillary Design for Fractional Tonnage Portable Air Conditioner, Journal of Advances in Mechanical Engineering and Science, Vol 3 (5).

Anonimous, (2015), Refrigerant R32, Diakses: 1 April 2018, www.daikin.co.th:https: //www.daikin.co.th/en/ serviceknowledge/ r32-Refrigerant/

Antunes, A., Filho, E., Mendonza, O., Souza, L., \& Bertoni, M., (2014), Experimental Evaluation Of Refrigerants R290, R32 and R410a In A Refrigeration System Originally Designed For R22, 10th International Conference on Heat Transfer, Fluid Mechanics and Thermodynamics (pp. 564-570). Orlando USA: HEFAT2014.

ASHRAE, (2001), Handbook Fundamental. ASHRAE, Inc.

Bolaji, B.O., (2012), Performance of A R22 Split-Air-Conditioner When Retrofitted With Ozone Friendly Refrigerants (R410A and R417A). Journal of Energy in Southern Africa, 16-22. 
Hadya, B., Prasad, A. M., \& Akella, S., (2015), Performance Assessment of HFC Group Refrigerants in Window Air Conditioning System. International Journal of Mechanical Engineering and Applications , 81-85.

Moran, M.J., and Shapiro, H.N., (2006), Fundamentals of Engineering Thermodynamics. Chichester, Inggris: John Wiley \& Sons, Inc.

Jadhav, S.S., and Mali, K.V., (2017), Evaluation of a Refrigerant R410A as Substitute for R22 in Window Airconditioner, IOSR Journal of Mechanical and Civil Engineering (IOSR-JMCE), 23-32.

Reddy, D., Bhramara, P., \& Govindarajulu, K., (2012), Performance and Optimization of Capillary Tube Length In a Split Type Air Conditioning System, International Journal of Engineering Research \& Technology (IJERT), 1 (7), 1-11. 